\title{
Una aproximación interdisciplinar al estudio del usuario de información: bases conceptuales y metodológicas
}

\author{
MónICA IZQUieRdo AlONSO \\ Fundación Séneca, Grupo Semiodoc, Fac. de Ciencias \\ de la D ocumentación, Universidad de Murcia, España \\ E-mail: semiodoc@ fcu.um.es
}

\begin{abstract}
RESUMEN
Ante la ausencia de un copusconceptual claramente reconocible, este trabajo pretende asentar las bases conceptuales y metodológicas para un estudio sistemático del usuario de información. En esta línea argumental, se propone un marco teórico integrador para el análisis global del usuario dentro del proceso informativo-documental desde presupuestos interdisciplinares. Se incluye también una caracterización de los estudios de usuarios teniendo en cuenta los objetivos, alcance y situación actual de este tipo de estudios, así como su relación con otras disciplinas próximas. El trabajo concluye con la propuesta de un modelo metodológico, desde la óptica de la pragmática del discurso documental, basado en el análisis de los autores, las categorías de documentos, los tipos de usuarios y las relaciones en esta tríada.
\end{abstract}

\section{AN INTERDISCIPLINARY APPROACH TOTHE STUDY OF THE END USER OF INFORMATION: CONCEPTUAL AND METHODOLOGICAL BASES MÓNICA IZQUIERDO-ALONSO}

\begin{abstract}
In response to the lack of a clearly recognizable conceptual body of literature on information users, the author shall attempt to establish the conceptual and methodological bases for the systematic study of information end users. To this end, an integrating, theoretical framework is proposed in order to achieve an in-depth, interdisciplinary analysis of theinformation end user working within the documentary-informational process. A description of the scope, situation and objectives of the literature on end-users is also provided, including a discussion of related disciplines. The paper concludes with a methodological proposal, from pragmatic approach to documentary discourse, based upon an analysis of the authors, the classes of documents, the kinds of users, and an analysis of the relationships within this triad.
\end{abstract}

Trabajo recibido

el 21 de abril de 1999

Trabajo aceptado

el 25 de mayo de 1999 


\section{INTRODUCCIÓN}

F l presente trabajo pretende servir de introducción general y elemental a la con$\perp$ ceptualización del usuario y al análisis de su contexto interdisciplinar. No es ni una presentación del "estado de la cuestión" propiamente dichani unaintroducción en profundidad a todo el amplio campo del ámbito del usuario. Surge ante la detección, por nuestra parte, de una significativa ausencia de un corpusconceptual claramente reconocible en los estudios de usuarios, y la necesidad consecuente de asentar unas bases epistemológicas que sustenten una verdadera teoría documental de la recepción. ${ }^{1}$

El usuario y el uso de la información documental son hoy en día el centro de las preocupaciones de los sistemas de información. Los estudios de usuarios se han convertido, pues, en muy poco tiempo, en uno de los temas centrales de investigación, ${ }^{2}$ generado una gran profusión de resultados empíricos o prácticos y, en menor medida, una reflexión teórica rigurosa por parte de los investigadores y profesionales delainformación. Los estudios deusuarios comenzaron desde el momento de su nacimiento a diversificar sus objetos de estudio, sus campos o áreas de aplicación y los métodos de investigación, de modo que actualmente existe una multitud de modelos que atienden a fenómenos puntuales muy variopintos que sólo comparten entre sí el pertenecer al dominio del usuario. Por otra parte, creemos preciso señalar la excesiva importancia dada a los aspectos cuantitativos relacionados con estos estudios, en detrimento de valoraciones cualitativas más exhaustivas. Este tipo de datos, aunque necesario y sin menosprecio de las áreas en las que se aplica, no es suficiente para explicar el funcionamiento de los servicios documentales y la dinámica de una transferencia óptima de información. Y más si consideramos que debemos operar con conceptos "subjetivos" como satisfacción, necesidad, demanda, y con toda una serie de procesos y actividades mentales relacionados con ellos.

Por todo lo dicho anteriormente, postulamos la necesidad de un enfoque interdisciplinar para el estudio de los usuarios de información, desde el ámbito de las Ciencias de la D ocumentación (centrándonos en la relación comunicativa en que discurre el fenómeno documental), que recojalas distintas aportaciones teórico-metodológicas de las técnicas y de la investigación de mercados, así como de la evaluación

1 El discurso teórico y las propuestas metodológicas presentadas en este artículo se enmarcan dentro de una de las líneas de investigación del G rupo SEMIO D O C, de la Universidad de Murcia, que atiende a la creación de una Teoría Pragmática del Discurso D ocumental en la que se atiende al análisis de la relación interdependiente entre el documento (y su contenido informativo) y cada uno de los actores del proceso informativo-documental (autor, intermediarios, usuario final).

2 Durante estaúltima década se han sucedido una serie de acontecimientos que han influido directamente en la consolidación de la disciplina que nos ocupa: la proliferación de la literatura, la progresiva inclusión de este tipo de estudios en los planes de estudio de las universidades, y la asidua presencia del tema del usuario en los foros de debate de las asociaciones profesionales, en los que se ponen sobre la mesa preguntas, problemas y expectativas que debe afrontar el estudio sistemático del usuario. 
institucional; los modelos explicativos de lapsicología cognitiva y ciencias afines; las técnicas y métodos de la investigación social, los modelos pragmalingüísticos; etcétera. $Y$ todo ello, desde una complementariedad de enfoques, si es que aspiramos a tener una teoría suficiente y adecuada del usuario.

\section{LA CONSTRUCCIÓN DEL CONTEXTO TEÓRICO DEL USUARIO. FUNDAMEN- TACIÓN EPISTEMOLÓGICA}

Las reflexiones teóricas relacionadas con el ámbito del usuario son escasas einsuficientes. D esde este presupuesto básico, abogamos por la necesidad de hacer una reflexión teorética y metodológica paralela y complementaria a la pura mecánica de la investigación práctica. Una vez hecha esta observación, en este apartado nos centraremos en cuestiones de tipo conceptual y denominativo. Prestaremos también especial atención a la naturalezamultidimensional del usuario como uno de los criterios básicos desde los cuales se han de fundamentar las propuestas taxonómicas de los tipos de usuarios.

\section{R eflexiones en torno al concepto de usuario. Un problema previo de ter- minología}

Las dificultades surgen desde el mismo momento de la conceptualización y denominación del término en cuestión, dada a la diversidad de acepciones y la duplicidad de valores coexistentes para designar el objeto de estudio. El uso polisémico de los términos, así como la falta de sistematización de los distintos significados, impide una clara conceptualización del mismo. Esta situación poco definida ha contribuido a la dispersión de enfoques a la hora de examinar el fenómeno del usuario. Aunque el término más aceptado es el de "usuario", la figura de éste ha recibido varias acepciones (destinatario, receptor de información, cliente, consumidor de información, usuario interno/ externo, usuario real / potencial, etcétera), y existe una clara matización respecto al contenido o a lo que designan los distintos conceptos, según veremos a continuación, aunque todos ellos ofrecen un sustrato común.

D esdela perspectiva etimológica, la palabra "usuario" procede del vocablo latino "usuanius". La raíz del término deriva a su vez de "usus" (uso) participio de "uti" (usar). El sufijo "ario" es una forma de nombre de la persona a cuyo favor se realiza algo. Tras esta breve nota sobre las raíces morfológicas y etimológicas del término, recogeremos las acepciones más comunes que de la palabra "usuario" nos ofrecen algunos diccionarios. El D iccionario de la Real A cademia E spañola (RAE , 1992), ${ }^{3}$ al margen de la acepción jurídica del término, que no se ajusta a nuestros intereses, recoge la siguiente definición para usuario: "Q ue usa ardinariamenteuna cosa." La

3 Real Academia Española. Dicionanio dela lenga epañda, 20ª ed., Madrid: Espasa-Calpe, 1996, Tomo II, p. 1360. 
definición del diccionario ideológico de Julio Casares (1988), ${ }^{4}$, se asemeja en su contenido a la presentada por el diccionario de laRAE: "Que usa ardinariamenteuna cosa o se sirve de ella". Se observará que en estas dos primeras definiciones el uso se halla matizado por un carácter temporal de asiduidad y frecuencia. Es un uso reincidente. María Moliner (1988) ${ }^{5}$ ofrece dos acepciones del término. En una primera "seaplicaa laspersonasqueusan dietoservido", para la segunda "seaplicaal quedisfita e usodedieta cosa”. En estaúltima definición, se restringe el campo semántico temporal del término y se amplia el objeto de uso: un servicio o una cierta "cosa". En un intento de abstracción podemos sustituir el término "cosa" por el de producto o bien informativo y determinar el tipo de servicio al que está destinado el uso: un servicio de información. Así pues, nuestro primer ensayo de definición quedará del siguiente modo. Un usuario de información será "todo aquel individuo que usa o utiliza un servicio de información o que disfruta el uso de un producto o bien informativo."

Los diccionarios y léxicos especializados en documentación, también aportan algunas definiciones específicas. Para Martínez de Sousa (1993)6 , un usuario es toda "persona que utiliza los servicios que puede prestar una biblioteca, centro de documentación o un archivo". D omingo Buonocuore (1976) ${ }^{7}$ caracteriza al usuario de una biblioteca como "... la persona que hace un aprovechamiento intensivo, activo y asiduo ... de sus servicios". El autor hace una diferenciación entre usuario y lector, y señala la inadecuación del término cliente como anglicismo adoptado para definir al usuario.

LaAssociation Française de Normalisation (AFNOR) ${ }^{8}$ se refiere al término como usuario final (utilisateur final), y lo define como "usuario que busca información para su propio uso", diferenciándolo del usuario intermediario (utilisateur intermédiaire o courtier) concebido como enlace 0 agente en los procesos de transferencia y gestión de información. Generalmente, este usuario intermediario se refiere a las empresas u organismos comerciales intermediarios entre el servidor y el usuario.

D esde el ámbito anglosajón se ofrecen similares definiciones. El glosario de la $\mathrm{ALA}^{9}$ no recoge el término, aunque incluye otros relacionados como user group, user education o user profile.

Tras esta elemental presentación lexicológica podemos inferir algunos elementos fundamentales y característicos del usuario de información: a) la utilización de un servicio de una unidad de información; b) el uso de un producto informativo, y c) el

4 Julio Casares. Dicionarioidelóǵcodelalengaespañda 2ª ed. Barcelona: G ustavo Gili, 1988, p. 849.

5 María Moliner. Dicianariodd usodd españd. 2 T. Madrid: G redos .- (Biblioteca Románica Hispánica V. Diccionarios, 5), 1988, p. 1427.

6 José Martínez de Sousa. DicionariodeBiblidoǵayCieniasafines, 2ª ed. aum. y act. Madrid, etc: FG SR; Madrid: Pirámide, 1993 .- (Biblioteca del libro; S), p. 861.

7 D. Buonocuore. Dicianario deBiblictedoǵa ... , 2ª ed. aum. Buenos Aires: Marymar, 1976, pp. 419-120.

8 AFNOR. V oabulariedela Dommentation 2ª ed. París: AFNOR, 1987, p. 119.

9 GlosarioALA deBiblidtedoǵayCienias dela Infomaaón Madrid: Díaz de Santos, 1988, p. 361. 
hábito o frecuencia con que se acude a dicho servicio o con el que se usa dicho producto. Así pues, podemos definir al usuariodeinfomacóncomo "aquel individuo que necesita información para el desarrollo continuo de sus actividades, ya sean profesionales o privadas, y que como tal utiliza un servicio o hace uso de un producto informativo." Según esta definición todos los seres humanos somos usuarios de información. La información es la base esencial del progreso de la sociedad y la necesitamos constamente para poder llevar a cabo las múltiples actividades que rea lizamos cada día. De este modo, necesitamos información puntual y práctica sobre una dirección, sobre una persona, o un organismo concreto; necesitamos una información cronológica determinada o sobre un acontecimiento de actualidad. Asimismo, necesitamos también información para tomar una decisión importante, o para satisfacer una curiosidad intelectual o estética.

La cuestión terminológica y conceptual se complica ante la afluencia de expresiones o significantes con los que se denomina adicionalmente al usuario (receptor, destinatario, cliente, consumidor de información). Esta imprecisión terminológica se acrecienta con los distintos matices existentes dentro de estos mismos términos. Así, se habla de usuario potencial y real, de usuario interno y externo, de usuario final o usuario intermediario, y de broker o courtier. Haremos una breve revisión de todos ellos con la intención de fijar los términos.

D esde los modelos de la teoría de la comunicación y la teoría dela información se emplean la expresiones reẹtory destimatariode información. D ichos términos no son incluyentes, pues si bien todo destinatario es un receptor deinformación no todo receptor tiene porqué ser el destinatario, y consiguientemente usuario, de una determinada información.

Esta acepción no ha calado muy hondo en el ámbito de las Ciencias de la D ocumentación ${ }^{10}$ y de ahí que, en principio, el término usuariosea el más difundido. Se podría emplear también la palabra "diente" o "consumidordeinformadón," los tres términos representan las funciones que debe cumplir un sistema de información encargado de la recepción, tratamiento y difusión de la información con el fin de sa tisfacer las necesidades informativas de una determinada comunidad. Es decir, el sistema de información debe poder ser "utilizado" en su dimensión de generador y transmisor de información, debe "estar al servicio del público" y debe "suministrar" los productos "puestos a la disposición de" este mismo público para satisfacer una necesidad de información.

'Cliente' y 'usuario' son dos términos utilizados con el mismo valor, aunque éste no sea real. Si bien, el término usuario es de uso muy generalizado anivel documental, no

10 Salvo en el uso de modelos para la explicación del fenónemo informativo-documental basados en los principios teóricos de las Ciencias de la Comunicación y de la Información. Cfr. el modelo de comunicación propuesto por J.M.Izquierdo Arroyo: “La Ciencia dela búsqueda secundaria I. Razón y misión de la CBS". En: DoumetaaóndelasCieniasdelaInformacón 13, 1990, pp. 87-111. Ver también del mismo autor: "Sdbrela transdurión(Meditaionessemidógicas) I: TransmisiónyDesustania aớn". En: Bdé́n MillaresCarlo 1/ 1, 1980, pp. 179-218. 
estamos muy acostumbrados a emplear el término diente quizás por el matiz de interés económicoque denota, aunque su uso se halle muy extendido en el ámbito de la gestión empresarial, para el cual los usuarios son clientes y deben ser tratados como tales. En la literatura anglosajona el uso de la expresión "customer" o "client" en sustitución de "user" o "patron" resulta significativo. El término cliente identifica a personas que utilizan un servicio y por lo tanto manifiestan interés en la variedady calidadde la oferta disponible. Es un término importado del sector mercadotécnico, junto con otros como necesidad, satisfacción, producto o mercado. Su uso comienza a generalizarse a finales de la década de los ochenta como elemento esencial de la calidad total, entendida como una filosofía de gestión orientada hacia la consecusión deun único objetivo: la satisfacción total del cliente/ usuario y, algo mucho más importante, de sus expectativas. La idea de cliente aporta un valor añadido a la significación de usuario. Y a no sólo se hace referencia al hecho de un determinado uso de una información, sino que se contemplan también las relaciones del cliente-usuario con el profesional del centro de información. Ya no se concebirá al usuario como un elemento ajeno al sistema de información sino que el cliente se integrará en el ciclo de la gestión de calidad y se le considerará como el eje central del sistema de información.

Junto a la generalización del término cliente, dentro de la "cultura" de la mercadotecnia, la gestión organizacional y la filo so fía de la gestión de calidad, se amplía el sentido del mismo, y se establece también una diferenciación entre el dienteextemoy el dienteintemo(personal, profesionales del servicio o de la unidad de información). El principio básico de la calidad no sólo buscará la satisfacción de las exigencias y necesidades de los clientes externos sino también la satisfacción del personal de la organización, motivándolo en el desarrollo de las habilidades personales y profesionales, fomentando su participación y potenciando su excelencia organizativa.

Surgen también especificaciones del término para diferenciar a aquellos usuarios que conocen y utilizan el servicio de quienes no lo hacen. La IFLA extiende la acepción dada al concepto de usuario a "todos los beneficiarios en potencia, y no sólo a los que utilizan los servicios en un momento determinado." Sanz (1994)11 define al usuariopotenaal como "aquel que necesita información para el desarrollo de sus actividades pero que no es consciente de ello," y quien por tanto no materializa su necesidad en una demanda. Elusuarioreal "no sólo es consciente de que necesitainformación sino que la utiliza frecuentemente."

O tro delos problemas conceptuales radica en la situación del usuario dentro dela realidad del proceso informativo-documental. Para algunos, el usuario sólo aparece al final de la cadena documental cuando se obtiene el documento en el servicio de préstamo 0 en el momento de la búsqueda bibliográfica (usuario final). En los sistemas que distribuyen grandes bases de datos legibles por ordenador, el usuario (broker,

11 Elías Sanz Casado. Manual dectudiodeusuanios Madrid; Salamanca: FG SR; Pirámide, 1994, p. 19. 
courtier) ${ }^{12}$ es la persona que consulta la información; de ahí que en la práctica a menudo sea éste un especialista o profesional de la información (usuario intermediario). Algunos ven en el usuario tanto al cliente de los servicios de información como al productor o generador de información. O tros lo incorporan al sistema de información como productor y cliente, o como enlace o agente de ciertos procesos de gestión y de transferencia de información. En cualquier caso, para definir al usuario es importante no perder de vista su miltiplicidaddefundiones No debemos olvidar que las actividades de cada persona en materia de información son fluctuantesy complejas, y que d papd di usuaniosesitúa en varios nivees Así, y tomando como ejemplo el caso de un investigador científico, éste podrá ser a la vez, y casi siempre simultáneamente: un productor deinfomacón por los artículos que escribe y que posteriormente serán tratados en la unidad de información; un usuariode los servicios de búsqueda bibliográfica cuando necesite localizar una documentación para preparar su investigación; un agentedetratamientopara la unidad de información en el caso de la realización de resúmenes de autor, y un agentededifusióngracias a la habilidad para transmitirle mensajes a cierto público, en determinados contextos o situaciones.

\section{El fenómeno multidimensional del usuario de información}

D e todo lo anterior se deduce que no podemos aproximarnos al usuario, sin establecer un perfil definido. A hora bien, coincidimos con $\mathrm{G}$ uinchat y Menou ${ }^{13}$ en que una de las dificultades a la hora de definir los perfiles de usuarios radica en que, a menudo, se han tratado de definir éstos respondiendo a la pregunta: "¿la información paraquiér?"; $y$, dado que cada individuo tiene preocupaciones diversas, deberíamos reformularnos la pregunta en los siguientes términos:" ¿la información paraque", es decir, “¿quéusopretende dársele a la información?”. E s preferible preguntarse aqué estádestinadalainfomaaóny no a quién, ya que cadain dividuo puede incluirse simultáneamente en varias categorías. Así, cuando un investigador quiere preparar un proyecto de investigación no tiene las mismas necesidades de información, ni los mismos comportamientos, que cuando va a escribir un artículo para una revista especializada o cuando necesita información para impartir un curso sobre un determinado tema. Las necesidades de información cambian en función de las tareasrealizadas y del djeitioy alcance de éstas. Así pues, el primer cometido seráidentificar los tipos de usuarios del centro implicado: ¿quién acude al centro, por qué y para qué?; determinar sus preferencias y expectativas; localizar sus hábitos informativos y detectar cómo perciben los problemas y qué necesidades proyectan a partir de ellos; definir los procesos que determinan la activación de su necesidad y los factores que

12 El usuariointemediano(courtier, broker) se sitúa entre los servidores de información y los usuarios, asistiendo a estos últimos en la selección y consulta de los bancos de datos. El término courtier se refiere más a un intermediario comercial entre el servidor y el usuario. (AFNOR, op. cit., p. 44).

13 Cfr. C, Guinchat y M. Menou. IntroduciónGeneal alasCieniasyTénicas delaInformadónyDoumenta

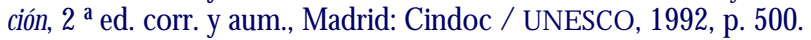


hacen posible que su necesidad se formule y se transforme en demanda; identificar sus intereses y competencias cognitivas; considerar sus valoraciones u opiniones, y determinar cuál es el grado de satisfacción obtenido y/ o esperado por ellos, etcétera.

Sin embargo estas variables subjetivas son de difícil objetivación, ya que el fenómeno humano es de naturaleza compleja, heterogénea y multidimensional. En consecuencia, las necesidades adquiridas, las condicionantes cognitivas que influyen en la percepción y en el procesamiento de la información, así como la valoración del grado de satisfacción obtenido, no son los mismos paralos distintos grupos deusuarios, los cuales tienen intereses diversos. Incluso tales intereses varían dentro del propio sujeto, como veremos más adelante.

\section{D elimitación de las categorías de usuarios}

Teniendo en cuenta lo dicho, las categorías de usuarios pueden definirse en función de dos tipos de criterios: sociodemográficos y psicosociológicos.

1.- Los criterios sociodemográficos son los de más fácil identificación y cuantificación, y sus variables o manifestaciones son las más ampliamente tratadas hasta ahora para definir las categorías de usuarios. Entre ellos englobaremos:

* La categoría socioprofesional o el grupo de actividad al que pertenece el usuario (dirección, investigación, servicios, etcétera).

* El sector específico al que pertenece la rama de actividad desempeñada (administración, industria, agricultura, etcétera).

* El nivel de formación y responsabilidad del usuario (directivo, técnico, personal de administración, responsable principal de un equipo de investigación, becario de investigación, etcétera).

* La naturaleza de la actividad o el tipo de actividad para la cual se busca la información.

* El objeto de la relación con los sistemas de información.

- La conciencia del universo existente de recursos informativos, etcétera.

2.- Entre los citeios psicoscaidógicsincluiremos:

* Las actitudesy valores del usuario con relación ala información en general, y con las unidades de información de modo particular.

* Los factores que determinan su necesidad.

* El comportamiento que manifiesta el usuario hacia las unidades de información (respecto a sus productos y diferentes servicios).

* Las condicionantes cognitivas y afectivas del usuario (competencia cognitiva, condicionantes culturales, experiencia personal ante el uso de información, actitudes y criterios evaluativos, etcétera) y una valoración de todo esto.

* Los procesos de adquisición y procesamiento de la información, y un estudio de esto. 
* Los fundamentos del desarrollo de la búsqueda de información y de comunicación de la información: cómo selecciona las fuentes de información, cómo formula sus preguntas, cómo escoge la información, preferencias por ciertos medios de información (determinados por la competencia cognitiva del usuario, los condicionantes temporales o espaciales, los socioculturales, etcétera ), el grado de fiabilidad que le concede a las diferentes fuentes de información, las condiciones materiales y los hábitos de trabajo, y valoraremos todo esto.

El uso dado a la información suministrada, etc. En el caso de la información científica, es preciso analizar todo el circuito de la información, desde su producción hasta los procesos de tratamiento y transferencia de información.

Pocas clasificaciones consiguen un consenso que resista al paso del tiempo y estén exentas de discusión. La mayor parte de las taxonomías presentan apartados de dudosa aceptación. No tenemos interés en ofrecer un vía única para tipificar los tipos de usuarios de información, antes bien proponemos la siguiente teniendo bien en cuenta que se trata de una relación de carácter descriptivo y orientativo. En ella pretendemos reflejar e incluir todo el contexto relacionado con el usuario ante el proceso comunicativo-documental al que nos venimos refiriendo (determinantes psicológicas, cognitivas, sociológicas, culturales, etcétera). Q ueremos subrayar el hecho de que hasta ahora se han tratado de definir los perfiles de usuarios atendiendo a quiénes el usuario que acude al centro de información: ¿la información para quiér; y se han identificado cuatro categorías de usuarios en función de su actividad (el investigador científico; el personal técnico-industrial; el gestor, administrador 0 político; el docentey el estudiante; y finalmente el ciudadano de a pie u hombre de la calle). ${ }^{14}$ Sin embargo, dado que cada individuo tiene preocupaciones diversas, deberíamos reformularnos la pregunta del siguiente modo: ¿quéusopretende darse a la información?¿cuál es la finalidad a la que está destinada la información demandada?, puesto que cada individuo puede incluirse a la vez en varias categorías de usuarios. No debemos olvidar tampoco que las necesidades de información cambian en función de las actividades realizadas y del djeivoy el alcance de éstas; y así como no son las mismas para los distintos grupos de usuarios con intereses diversos, también varían dentro del propio sujeto dependiendo del entorno en el que se produce la necesidad y los objetivos que se pretenden conseguir.

14 Una de las tipologías sobre las que más se ha escrito ha sido la agrupación de los usuarios según su campo de actividad, y se han determinando las cuatro categorías señaladas. Los estudios de usuarios han demostrado que, en general, las pautas de comportamiento, hábitos y necesidades de información, dentro de determinados campos de afinidad, son similares. Esta clasificación constituye un primerpunto de partidaya que permite distribuiralos usuarios de un modo homogéneo, lo que facilita su estudio, sin embargo debe ser completada con otros criterios de evaluación.

Cfr. E. Sanz. Op at, pp. 38-44. 
Teniendo en consideración todo lo señalado, nuestra propuesta taxonómica atiende a los cuatro siguientes criterios complementarios de clasificación:

\section{1.- Criterios referentes a las caracteństicas pragmáticas de la situación comu-} nicativa. La información, los hechos, se comunican en un contexto social determinado y están dotados de una funcionalidad intencional. A simismo, la búsqueda y recuperación de información también se realiza desde ciertos presupuestos intencionales y desde una situación comunicativa concreta.

2.- Criterios referentes a las caractenísticas propias del usuario (incluyen variables sociodemográficas, y una serie de condicionantes cognitivas y afectivas que influyen en la percepción y en el procesamiento de la información así como en el índice de impacto de la satisfacción percibida).

Por lo común los usuarios siguen unas pautas de información muy generales dentro de determinados campos o áreas afines, gracias a lo cual se ha podido establecer una clasificación de los distintos grupos de usuarios, con el fin de facilitar su estudio. Así, tal y como señalan $\mathrm{G}$ uinchat y Menou, ${ }^{15}$ podemos distinguir tres grandes categorías según el tipodeadividad desempeñadapor el usuario:

* Losque todavíano pertenecen a la vida activa (estudiantesy universitarios).

- Los que pertenecen a la vida activa y cuyas necesidades informativas provienen de su profesión. Éste tipo se clasifica de acuerdo con:

- Su función principal (dirección, gestión y administración, docencia e investigación, etcétera).

- Su sector de actividad y/ o su especialidad (política, industria, agricultura, economía, tecnología, investigador en humanidades, ciencias sociales, ciencias experimentales, etcétera).

- Su nivel de formación y de responsabilidad (directivos, técnicos, administrativos, miembros de un grupo de investigación, becarios de investigación, etcétera).

* El ciudadano, considerado bajo el aspecto de sus necesidades de información general, que están ligadas a la vida social.

En cada un de estos tres casos, y tal como señalamos anteriormente, el usuario 0 categoría de usuarios prefiere ciertos recursos de información que vienen determinados por su formación, posición jerárquica y relaciones laborales, condiciones materiales y hábitos de trabajo, condicionantes cognitivas, situacionales, etcétera.

15 Guinchat y Menou, Op at, p. 499. 
3y 4.-Criterios relacionados con el tipo de necesidad informativa generada y las caracteństicas de la información requeridas para satisfacerla.

* Tipo de necesidad informativa: información científico-técnica; información general; información de actualidad; información puntual y precisa sobre un dato de la vida social; información de divulgación; etcétera.

* Uso al que está destinada la información: aprendizaje, docencia, investigación, interpretación, toma de decisiones, etcétera.

* Nivel de especificidad de la información suministrada: divulgación, información de síntesis; información muy elaboraday específica; actualizaciónes; información de alerta o puesta al día; información sobre el estado de una cuestión o materia; primera aproximación a un tema; información exhaustiva sobre todo lo publicado sobre una materia; información puntual y precisa; etcétera.

* Tipo de recurso informativo a suministrar. índices de citas y boletines de resúmenes; informes sobre patentes; catálogos de normas; informes técnicos; boletines informativos; catálogos comerciales; diccionarios, manuales y obras de síntesis; monografías especializadas; etcétera.

* N aturaleza de la información y tipo de presentación de la misma: textual, gráfica, factual, mixta.

* Grado de elaboración de la información: información primaria, secundaria o terciaria.

\begin{tabular}{|c|c|}
\hline \multicolumn{2}{|c|}{$\begin{array}{c}\text { Criterios para una clasificación de los usuarios de infor- } \\
\text { mación }\end{array}$} \\
\hline $\begin{array}{l}\text { Caracteństicas de la situación } \\
\text { comunicativa }\end{array}$ & $\begin{array}{l}\text {-Funcionalidad intencional y pragmática del } \\
\text { contexto comunicativo }\end{array}$ \\
\hline $\begin{array}{l}\text { Caractenísticas propias del } \\
\text { Usuario de información }\end{array}$ & $\begin{array}{l}\text {-Tipo de actividad desempeñada } \\
\text {-Contexto cognitivo y contexto afectivo } \\
\text {-Competencias comunicativas y discursivas }\end{array}$ \\
\hline $\begin{array}{l}\text { Caracteństicas de la necesidad } \\
\text { de información requenida }\end{array}$ & $\begin{array}{l}\text {-Tipo de necesidad informativa } \\
\text {-Uso al que está destinada la información }\end{array}$ \\
\hline $\begin{array}{l}\text { Caracteństicas de la informa- } \\
\text { ción a suministrar }\end{array}$ & $\begin{array}{l}\text {-Nivel de especificidad de la información } \\
\text {-Naturaleza de la información suministrada } \\
\text {-Grado de presentación y elaboración de la } \\
\text { información } \\
\text {-Tipo de recurso informativo }\end{array}$ \\
\hline
\end{tabular}




\section{OTRAS CUESTIONES TEÓRICAS CONCERNIENTES A LOS ESTUDIOS DE USUARIOS}

Una vez revisados algunos de los principios fundamentales para la conceptualización del usuario, formularemos las bases necesarias para afrontar con sistematicidad y rigurosidad un estudio de este tipo. Nos enfrentamos a un campo de investigación amplio y variado, dada la propia naturaleza multidimensional del usuario. Trataremos de precisarlo, de circunscribirlo, a través de un análisis de conceptos y objetivos, así como del examen delos ámbitos o sectores de estudio en los que han podido desarrollarse sus características y manifestaciones más importantes. Señalaremos igualmente cómo pueden plantearse los estudios de usuarios desde la perspectiva de la pragmática del discurso documental.

\section{A proximación conceptual}

Es difícil dar una definición exacta de lo que se entiende por un estudio de usuarios, ya que se trata de un fenómeno dinámico y complejo en el que intervienen un número importante de variables. El conjunto de las definiciones tiene un sustrato común; el estudio de la relación entre la información y el usuario. Difieren, sin embargo, los aspectos y las características que definen esta relación. Un grupo de definiciones centra su interés en el análisis de las características del uso de una determinadainstitución documental (biblioteca, centros de información, archivo o museo), o deun determinado servicio o recurso de información. D esdeestos supuestos, Clason (1976: 401)16 concibe los estudios de usuarios como: "investigaciones sobre las necesidades y características de los usuarios de una biblioteca o centro de información." Elías Sanz (1994: 31)17, desde una óptica bibliométrica, sitúa la esencia de la definición en los hábitos de comunicación y en el consumo de información. El autor concibe, pues, los estudios de usuarios como: "el conjunto de estudios que tratan de analizar cualitativa y cuantitativamente los hábitos de información de los usuarios, mediante la aplicación de distintos métodos, entre ellos los matemáticos principalmente estadísticos a su consumo de información."

Consideramos, sin embargo, que estas definiciones, al excluir de su formulación toda la serie de presupuestos "subjetivos" relacionados con el ámbito del usuario (de carácter psico-sociológico, cognitivo y cultural), resultan un tanto restringidas e incompletas. En consecuencia proponemos una definición en la que integramos todo el contexto global en el que se inserta la figura del usuario. ${ }^{18}$ Basándonos pues

16 W.E. Clason. DidionaryofLibrarySäene, InformationandDoumentation Amsterdam: Elsevier Scientific Publishing, 1976.

17 Sanz. Op Cit, p. 31.

18 Dicho marco situacional determinala configuración del usuario y condiciona toda una serie de factores como la necesidad; el comportamiento; el hábito o el uso de un determinado recurso o servicio de información; la satisfacción percibida; etcétera 
en las propuestas del enfoque cognitivo y en los principios de la pragmática, concebimos los estudios de usuarios como:

El conjunto de estudios que tratan de analizar cualitativa y cuantitativamente la interacción entre la información en todas sus dimensiones y el usuario, incluyendo en su valoración el contexto situacional o pragmático en el que éste se inscribe. A ellos competerá la valoración de:

* La mecánica de creación de hábitos informativos.

- El consumo de información de los usuarios.

— El análisis de comportamientos y actitudes individuales o colectivas ante la información.

* Los procesos que determinan la activación de una necesidad y los factores que hacen posible que ésta se transforme en demanda.

* Las características del uso de la información por parte del usuario (es decir, cómo opera con ella, los procedimientos empleados para adquirir los conocimientos y recuperarlos cuando han de serutilizados ...).

* La mecánica de percepción del ser humano ante una determinada información o recurso informativo o ante la oferta de un determinado servicio o prestación.

- El modelo de procesamiento de la información (competencia cognitiva del usuario de información; formas y estrategias de pensamiento; condicionantes de la adquisición, reconocimiento y representación de la información; etcétera).

* El modo y el nivel en el que se representan estas necesidades de información en el sistema; etc.

Elalcance de estos estudios cubre tanto las investigaciones decolectivos en general (como por ejemplo el estudio de la comunidad de los científicos españoles) como los estudios concretos de un grupo de usuarios de una determinada unidad de información, o incluso los de un servicio concreto o un recurso en particular.

\section{O bjetivos de este tipo de estudios}

En un esfuerzo de síntesis por aunar eintegrar todos estos matices complemetarios de los estudios de usuarios, podemos resumir sus objetivos en las siguientes categorías:

a) El análisis de las necesidades: el contenido y el tipo de información buscado, desde un punto de vista cuantitativo y cualitativo. Este análisis permite definir los productos, los servicios y hasta la clase de unidad de información que mejor se adapte a las distintas circunstancias.

b) El análisis de los comportamientos de la información: indica cómo se satisfacen normalmente las necesidades; aclara el contexto de los productos y servicios; precisa las condiciones que deben cumplirse, y permite definir el tipo de preparación y/ o de formación de los usuarios.

c) El análisis de motivaciones y actitudes: valores; deseos expresados y ocultos frente a la información y a las actividades relacionadas con ella; expectativas; nivel desatisfacción; imagen (idea que se hace el usuario) de los servicios deinformación 
y de sus profesionales; etcétera. Este análisis permite explicar el fundamento de los comportamientos y de las necesidades.

d) Elanálisis del consumo y producción de literatura científica se centra en estudios bibliométricos descriptivos (producción, colaboración y análisis de materias) y en el análisis de citas.

e) El análisis de modelos de procesamiento de la información, atiende los fenómenos psicocognitivos que se evidencian en cada una de las fases del proceso documental (creación, tratamiento, difusión, uso e influencia de la información); los contextos cognitivos de la recepción de lainformación; los mecanismos y motivaciones de la percepción; los factores que determinan la atención y el reconocimiento de información; los procesos implicados en la organización y representación del conocimiento; las intenciones comunicativas de los actores informativos; el estudio de los efectos comunicativos producidos en la mente de los usuarios; el análisis del uso de la información; la valoración de las actitudes, motivaciones y comportamientos de los usuarios; etcétera.

\section{"Excursus" histórico}

Los primeros estudios de usuarios, según el profesor Elías Sanz (1994:45)19 se sitúan hacia 1920 en el ámbito norteamericano. Se dedicaron al análisis de aspectos relacionados con el análisisdelasfuentes deinfommaónutilizadasporlos distintoscdeetivosinvesticadares el estudiodelos hábitos decommicaciónentreloscientíficos 0 la valoración de uso quesehaáadelossistemasyservicosdeinfomaaón Estas primeras investigaciones fueron muy elementales, y hubo que esperar hasta finales de los años 50 para encontrar orientaciones más elaboradas sobre el tema. Sin embargo, es hacia la mitad de los años 60 cuando empieza a tomar cuerpo esta disciplina y sale a la luz un número importante de trabajos sobre los hábitos y necesidades de información de los científicos. A partir de esta fecha va surgiendo también una preocupación por los estudios relacionados con los hábitos, yneesidades deinfomacón da usuarioen general, y comienzan a tenerse en cuenta los resultados de estas investigaciones para la gestión de las unidades de información. No obstante, seráa inicios de los años 80 cuando cobrará gran importancia esta línea temática, gracias a la generalización de los modelos de gestión de calidad aplicados a los sistemas de información científica. El principio básico de esta filosofía de gestión será la búsqueda de la satisfacción de las exigencias y necesidades de los clientes, y más aún, de sus expectativas; lo que trasladado a la institución documental se traduce en la optimización de los flujos de información y conocimiento. El enfoque de estos estudios se centra en la evaluación

19 Para obtener una información complementaria más detallada sobre la evolución histórica de los estudios de usuarios. Ver , Elías Sanz. Manual deectudios deusuarios Madrid, Fundación G ermán Sánchez Ruipérez, 1994, pp. 45-87. 


\section{Investigacón Biblidtedógica v. 13 No. 26 enero/ junio de 1999}

delosservicosdeinformacóna través de las valoraciones de los usuarios con el objetivo de instalar una política de mejoramiento de las unidades de información, al intentar orientar el producto o servicio de información en función de las necesidades del cliente/ usuario. En esta fase, influida por la gestión desde la óptica de la calidad, se cubren aspectos tales como: detección y análisis de las necesidades de información de los usuarios; identificación de las motivaciónes, actitudes y deseos respecto a la unidad deinformación y a los productos informativos; valoración del grado de satisfacción recibiday/ o esperadaante determinado servicio o producto; sensibilización y formación del usuario; etcétera.

Paralelamente dentro del ámbito bibliométrico se siguen desarrollando los estudios relacionados con el usuario científico, que se centran en el consumbylaproducción deliteratura dentífica.

D esde finales de los años 80, coincidiendo con un crecimiento sorprendente de algunas disciplinas científicas como la psicología cognitiva, la teoría de la comunicación, la pragmática o la propia inteligencia artificial, el entorno y el objeto deestudio cambió significativamente dentro del paradigma teórico que dominaba las Ciencias de la D ocumentación e Información. El concepto de usuario desde una perspectiva pragmático-cognitiva cobra entonces especial importancia, y el eje central de interés en la mayoría de las investigaciones se traslada del sistema de información al usuario. Será sobre todo en los años 90, de la mano de laInformation Retrieval, cuando surge la preocupación por redefinir al usuario con base en enfoques cognitivos. Bajo esta concepción, en el análisis del usuario se incluyen toda una serie de presupuestos y contextos subjetivos. Es decir, se considera todo el contexto global en el que el usuario se mueve para buscar y recuperar información (intereses individuales, conocimientos generales, competencia pragmática, bagaje de experiencias previas, conocimiento de los recursos informativos, etcétera).

D esde esta perspectiva cognitiva, un sistema de recuperación de información (SRI) se caracteriza porque en ambos extremos del canal de comunicación tienen lugar procesos cognitivos. El mensaje aquí no sólo es portador de información objetiva (concocimiento objetivo que un autor ha depositado en un texto), contiene también otros elementos pragmáticos que determinan el contexto de la emisión, dotan al mensaje de significación einfluyen en la recepción de éste. Estos elementos subjetivos, si así queremos llamarlos, son quizá los responsables de que a la hora de recuperar información, un determinado documento, entre varios de la misma materia, sea 0 no relevante para un determinado usuario.

Esta última orientación está recibiendo actualmente una gran aceptación entre los investigadores, gracias al desarrollo paralelo de las investigaciones en psicología cognitiva e inteligencia artificial. A simismo, está acaparando la atención en los proyectos de investigación sobre organización y representación del conocimiento (análisis de modelos cognitivos en los procesos de reconocimiento y representación de lainformación) y en el ámbito de las técnicas avanzadas de recuperación de 
información. ${ }^{20} \mathrm{Al}$ mismo tiempo considera el estudio de las distintas estructuras y procesos de la mente de los usuarios y su traducción a estructuras de contenido informativo, al ser incluidas en el sistema documental. Finalmente analiza el grado de interacción que existe entre la representación en el sistema de estas estructuras cognitivas del usuario, y el reconocimiento de esa representación por parte de éste. A tiende también al uso que hace de estas representaciones el usuario.

D entro de este nuevo enfoque situacional, surge una nueva red de conceptos que debe ser reconsiderada e integrada en el acervo documental. El concepto de daminio temáticose amplía y de la de designar el conjunto representado por el conocimiento propio de un campo temático o disciplina para incluir otras características que pertenecen a la efera cognitiva de los autores y los usuarios, lo cual afectará significativamente la valoración dela información relevante. Estaúltima también amplía sus miras diferenciando entre lo que es una revancia temática (significado implícito, semántico o de representación temática) y lo que es una rdeancapsicdóġa osituado nal . ${ }^{21}$ La relevancia se convierte pues en algo variabley dinámico. No puede entenderse sólo como la recuperación de una determinada temática de interés para el usuario. Ha de incluir toda una serie de presupuestos contextuales o cognitivos que parten de la óptica del modelo mental del usuario, y que son tanto o más importantes que la precisión temática. Es importante tener en cuenta estas consideraciones a la hora de proponer modelos ya sean teóricos o prácticos para el estudio del usuario de información, e incluirlas como criterios de clasificación en las propuestas taxonómicas.

\section{Á mbitos de aplicación de los estudios de usuarios}

En cuanto alosámbitos o dominios de aplicación de este tipo de estudios, es preciso señalar que se caracterizan por la pluralidad de enfoques, planteamientos y mé todos. No pretendemos hacer una relación detallada y exhaustiva de los campos 0 áreas de investigación que circunscribe este tipo de estudios; sin embargo, hemos re cogido los más usuales para hacernos una idea de sus distintos objetos y aplicaciones. El problema ante esta heterogeneidad deinvestigacionesy paradigmas metodológicos radica en la dispersión y pérdida de visión de conjunto, así como en una posible falta de conceptualización coherentey una teorización sistemáticay rigurosa del usuario. En nuestra opinión, uno de los retos con los quenos enfrentamos es encontrar medios efectivos para organizar este material con el propósito de desarrollo tanto teórico como práctico.

20 Esta dimensión cognitiva es el objeto principal de la investigación de Ingwersen y ha sido tratado también por autores como Ellis y Belkin. Cfr. Ingwersen. InfomationRexieal interaction Londres, Taylor G raham, 1992; D . Ellis. NewHoizontsinInfomationRemieal. Londres: The Library Association, 1990; Belkin, N: "The cognitive viewpoint in Information Science". En: Joumal ofInformation Saiere, 16(1), 1990, pp. 11-16.

21 Cr. Stephen Harter. "Psychological relevance and Information Science". En:Jamal oftheAmerican Sociey for Infomation Saiere 43(9), 1992, pp. 602-615. 


\section{1.-Evaluación institucional. Gestión de calidad total aplicada a los servicios} de información, Técnicas de investigación de mercado, marketing. Estas "disciplinas" abarcan aspectos tales como: el conocimiento de los usuarios; la detección y análisis de las necesidades de información; la identificación de motivaciones, actitudes y deseos respecto a un servicio/ producto determinado; la evaluación de servicios y productos a través de las opiniones de los usuarios; el estudio del grado de satisfacción respecto a un producto y/ o servicio, etc. Sus aplicaciones se centran mayoritariamente en el diseño y evaluación de los sistemas de información. ${ }^{22}$

2.- Bibliometría y estadística documental, centradas en el análisis de la producción y consumo de literatura científica, incluye estudios cuantitativos de diversos aspectos de la literatura científico-técnica; identificación de la estructura y dinámica de los colectivos investigadores; detección de especialidades emergentes; predicción de tendencias de publicación sobre temas específicos; etcétera.

3.- Instrucción y Formación de usuarios, con aplicaciones referentes a la introducción al uso de un servicio o herramienta documental, etcétera.

4.- Actualmente están cobrando gran importancia los estudios relacionados con los dominios de las Ciencias Cognitivas. Ello supone la integración de los modelos psicocognitivos en el proceso documental (análisis de la estructura cognoscitiva, procesos mentales de adquisición, organización y transmisión del conocimiento, etc.étera).

\section{HACIA UNA TEORÍA INTERDISCIPLINAR DEL USUARIO}

En un principio las ciencias suelen dividirse en función de su objeto de estudio, así como por la forma específica en la que se aborda dicho objeto. Hoy en día, se pre tende separar los objetos de las ciencias y englobar o juntar las disciplinas parciales que se fijan en ellos. En este sentido, el estudio del usuario se vincula con otras disciplinas, todas ellas relacionadas, en tanto se fijan dealguna forma en el mismo objeto, tal y como lo reflejan los dominios de relación presentados a continuación entre ciencias afines:

\section{* Psicología Cognitiva y Ciencias afines.}

Procesos cognitivos presentes en la producción, procesamiento y transferencia del conocimiento científico.

* Ingenienía del Conocimiento y Tecnologías de la información.

22 Como ejemplo de un modelo concreto dentro de esta orientación. Cfr. M. Izquierdo Alonso; J. Ruiz Abellán ; J.T. Piñera Lucas. "Un modelo de gestión de calidad total para las bibliotecas públicas". En: SCIRE: RepresentacónyOrganizacóndd Conoimiento 2 (1), 1996, pp. 63-92. Sobre la metodología de encuesta aplicada al estudio de la percepción de los usuarios en centros documentales, y más concretamente para el diseño de preguntas en la elaboración de cuestionarios ver. J. Ruiz Abe llan; M. Izquierdo Alonso; J.T. Piñera Lucas. "A portaciones en torno al usuario de información”. En: Reista deDoumentacoón delas Cienaias dela Infomadón, 21, 1998, pp. 11-75. 
* Teoría de la Información y Comunicación.

Aplicaciones de las investigaciones del proceso general de comunicación al ámbito del proceso documental.

- Ciencias del Lenguaje: Semiótica. Psicolingüística. Sociolingüística.

* Epistemología. Gnoseología. Filosofía de la Ciencia.

* Sociología de la información. Sociología del conocimiento y de la Ciencia.

- Psicología social (estudio de actitudes, comportamientos individuales y colectivos ante la información, usos efectivos dados a la información, coeficientes de satisfacción, etcétera).

* Técnicas de Evaluación y Gestión (Evaluación de Instituciones, Gestión de Calidad, Investigación de Mencados).

* Ciencias de la Información y Documentación:

- Organización y Representación del Conocimiento.

- Sistemas de Almacenamiento y Recuperación de la información.

- Técnicas bibliométricas aplicadas al estudio de los procesos de transferencia de información científica. Estudios de producción y consumo de literatura científica.

Pero, ante el peligro de la dispersión, creemos conveniente intentar una unificación de enfoques teórico-metodológicos. D ebemos integrar en un cuerpo teórico único las distintas disciplinas implicadas, y analizar la relación que guardan éstas entre sí, dentro del marco específico de lo que podríamos llamar una teoría rigurosa y sistemática del usuario. En este sentido, conviene recordar que no se trata de un conglomerado de elementos diversos, sino de la integración y la elaboración de algo nuevo a partir de ellos. A simismo, señalamos la necesidad de reivindicar un espacio propio para los estudios de usuario, ubicándolos en el lugar apropiado del cruce interdisciplinar, por un lado, y definiendo paralelamente su estatus específico dentro de las Ciencias de la D ocumentación.

Tras la aproximación al mundo de los usuarios como fenómeno multidimensional, y advertidala necesidad de definir un marco teórico interdisciplinarpara su estudio, con base en laintegridad y complementariedad de enfoques, pasaremos a la formulación de un nuevo modelo metodológico para el estudio del usuario desde la perspectiva del proceso comunicativo documental.

\section{CONSTRUCCIÓN DE UN MODELO TEÓRICO INTEGRADOR PARA EL ESTU - DIO DEL U SUARIO}

Para la construcción de este modelo tendremos en cuenta el análisis interdependiente de cada una de las variables del proceso informativo-documental: el análisis de los autores, las categorías de documentos, los tipos de usuarios y las relaciones entre esta tríada. Partimos del estudio del proceso comunicativo por medio dedocumentos, desde el punto de vista de la correspondencia existente entre el pensamiento 


\section{Investigacón Biblictedógica v. 13 No. 26 enero/ junio de 1999}

"subjetivo" del autor y el del receptor-usuario, tal y como ese pensamiento queda "cristalizado" en el documento. Consideramos la intención comunicativa del emisor o productor de información, los intereses cognoscitivos y las competencias discursivas del destinatario-receptor, el mensaje como portador de conocimiento, y los efectos surgidos en el destinatario tras su recepción.

D entro de esta dimensión pragmáticaincluiremos la compleja situación comunicativa en la que se produce la emisión y la recepeción de lainformación. Entre los aspectos a tener en cuenta, habrán de considerarse los contextos cognitivos de la producción y recepción de la información; los mecanismos y motivaciones de la percepción; los factores que determinan la atención y el reconoimiento los procesos implicados en la organización y representación del conocimento; las intenciones comunicativas de los actores informativos; el estudio de los efectos comunicativos producidos en la mente de los usuarios; ${ }^{23}$ el análisis del uso de la información; la va loración delas actitudes, motivaciones y comportamientos delos sujetos; etcétera.

a) E STUDIO DE LOSAUTO RES. Se trata de analizar las relaciones, a nivel mental, que existen entre los autores y los usuarios por medio de los documentos científicos; es decir, se buscaidentificar la correspondencia entre el pensamiento del autory el del usuario, tal como ese pensamiento queda materializado en el documento.

En el estudio de la dimensión situacional del emisor, incluiremos el reconocimiento de sus creencias, aptitudes, intereses, competencia discursiva, objetivos pretendidos con la comunicación, cultura, localización espacio-temporal de la emisión, etcétera). D e este modo, centrándonos en la perspectiva de la producción del texto, es decir en el autor, podremos analizar la organización, lajerarquía, y la importancia de las ideas que el autor quiere transmitir así como los factores dependientes de los aspectos técnicos y gráficos (formato, tipo de letra, ilustraciones, gráficos, esquemas, tablas, etcétera) que puedan incidir de forma positiva o negativa en la percepción y legibilidad de lo impreso. Consecuentemente, a través de su texto escrito, un autor puede ser estudiado con base en su capacidad para expresar las ideas, relacionar conceptos, argumentar, y elaborar proposiciones coherentes y suficientemente representativas. Se puede valorar también su destreza para presentar una información textual estructurada, a partir de su capacidad de seleccionar un vocabulario apropiado, de usar una sintaxis y estilística adecuadas, etcétera. Se puede, en definitiva, analizar la capacidad del escritor para organizar la presentación de las ideas que desea comunicar. Así, un determinado autor, y según su propia competencia, organiza de un determinado modo la materia que trata en razón del lector-tipo por él previsto. Por tanto, se pueden estudiar como factores determinantes de la emisión y de la recepción: la manera como se

23 El contenido de un documento no es sino el efecto producido en la mente del lector con ocasión de que éste decodifica el mensaje del documento, y ese efecto no viene dado sólo por el documento, también obedece a una serie de circunstancias internas y externas al lector. (Cfr. "El concepto de 'relativización del contenido'”, en J.M.izquierdo A rroyo. Laaganizaióndbamental de conoimierto I/ 1: El marcodbametal. Madrid: Tecnidoc, 1995, p. 288 ). 
trata la materia, el carácter del autor, el carácter del lector previsto, etcétera. Por otra parte, desde el punto de vista de la comprensión e interpretación (asimilación), se pueden formular reglas científicas a las que deberían atenerse los autores a fin de obtener el máximo de "lecturabilidad" (reglas para captar y retener la atención del receptor, para hacer comprender las nociones, producir emociones, etcétera).

El objetivo final de estos estudios será disponer de una técnica efectiva para la elaboración de documentos.

b) E STUDIO DE LOS DOCUMENTOS. Podemos también tomar como referente de estudio el mismo texto o el contenido informativo del mensaje escrito, bien desde lavertiente de su contenido temático o bien desde la estructura organizativa de ese contenido, de modo que se puedan generar estrategias de procesamiento de la información a través de la identificación y reconocimiento de esas estructuras. Con ello pretendemos investigar la relación que se da entre ciertos aspectos de los mensajes científicos y las características psicocognitivas del receptor. Clasificaremos las obras atendiendo a los siguientes criterios:

* Tipo de texto/ documento.

* Grado de especialización.

* Objetivos del texto/ documento.

* Área o disciplina a la que pertenecen los contenidos textuales.

* Facilidad de acceso al contenido.

* Grado de asimilación del contenido (asimilabilidad).

* Nivel de información que proponciona el documento.

* Grado de estructuración del contenido: tratamiento de una cuestión en particular; exposición de una materia de un modo sistemático y completo, primera aproximación al tema, información del estado de la cuestión, etcétera.

* Valoración del tipo de información y forma de presentar esa información

* Nivel de representación: primario, secundario, terciario.

* Naturaleza de la información (textual, gráfica, factual, mixta).

* Grado de abstracción de la información presentada o suministrada: modo de estar representado el contenido relacionado con el tipo de proceso mental (razonamiento) implicado en el tratamiento de los datos. Es decir, valoración del grado de comunicación (conexión entre el receptory el documento) o distancia psico-gnoseológica.

* Exactitud del contenido informativo.

Grado de Completud.

* Capacidad de sugenencia o fuerza sugeridora de los contenidos, etcétera. 
C) ESTUDIO DE LOS TIPOS DE USUARIOS. El usuario de información también debe ser estudiado desde esta óptica de la psicología cognitiva y con una dimensión y competencia pragmática. Una de las tareas importantes para los profesionales de la documentación es tratar de entender cómppuedeysudeasimilare sujetoht mano es decir, debe analizary estudar d conjuntodeproesos querealiza d individuoala hara deasimilarinformacónnuea (modos de adquisición de la información; la interacción entre percepción y conocimiento; los procesos implicados en la percepción; las condicionantes de la atención; el razonamiento; la intuición; la asimilación crítica; la comprensión y la interpretación; los procedimientos analítico-sintéticos relacionados con el procesamiento de la información; los modos de representación del conocimiento; etcétera). Nuestro objetivo último será el establecimiento y delimitación de "perfiles" o tipos de la conducta de los humanos en cuanto procesadores de información, con el propósito final de diseñar estrategias de representación y transmisión de información de un modo más eficaz. Valoraremos también los moddos situacionales o factores internos y externos que determinan los comportamientos, hábitos, expectativas y necesidades de los usuarios hacia determinados tipos de información.

Para ello, consideraremos una serie de indicadores:

* Pertenencia a un determinado grupo de actividad, área o disciplina científica.

Condicionantes temporales y espaciales del usuario.

* Competencia cognitiva, nivel de experiencia del sujeto dentro del campo en el que intenta asimilar nueva información (no es lo mismo un investigador experto, que un novel, un estudiante de primer ciclo, etc.). El investigador cualificado cuenta con unos conocimientos previos y unos esquemas mentales relacionados con la nueva información que procesa. Es un buen procesador de la información y organiza rentablemente los conocimientos dentro del (os) campo(s) en que posee experiencia. Además, el usuario experto está interesado en comprender las relaciones del documento con los conocimientos que ya posee y, especialmente, en la información nueva contenida por el documento. Esto ha de tenerse especialmente en cuenta por parte del documentalista a la hora de seleccionar cualitativamente la información. Y para ello se han de definir perfiles de competencias e intereses desde el punto de vista lector-usuario.

Marco relacional o de trabajo / Contexto cognitivo (pertenencia a un grupo de investigación determinado, etcétera).

Condicionantes culturales (influencia acumulada: formación académica, etcétera).

Formas y estrategias de pensamiento.

Capacidad de percepción del sujeto cognoscente. 
* Hábitos ante la información por parte del usuario; es decir, cómo opera con ella, procedimientos empleados paraalcanzar los conocimientos y recuperarlos cuando han de ser utilizados, etcétera.

* Experiencia personal del usuario.

* Elementos afectivos, emocionales.

* Influencias informativas, documentales y sociales.

* Creencias, actitudes, criterios evaluativos, etcétera.

* Tipo de necesidad informativa: información científico-técnica; información general; información de actualidad; información puntual y precisa sobre un dato de la vida social; información de divulgación; etcétera.

- Uso al que está destinada la información: aprendizaje, docencia, investigación, interpretación, toma de decisiones, etcétera.

* Nivel de especificidad de la información suministrada: divulgación; información de síntesis; información muy elaborada y específica; actualizaciones; información de alerta o puesta al día; información sobre el estado de una cuestión o materia; primera aproximación a un tema; información exhaustiva sobre todo lo publicado acerca de una materia; información puntual y precisa; etcétera.

- Tipo de fuente informativa a suministrar índices de citas y boletines de resúmenes; informes sobre patentes; catálogos de normas; informes técnicos; boletines informativos; catálogos comerciales, diccionarios; manuales y obras de síntesis; monografías especializadas; etcétera.

* Naturaleza de la información a suministrary tipo de presentación de la misma: textual, gráfica, factual, mixta.

* Grado de elaboración de la información: información primaria, secundaria o tenciaria.

D) RELACIONES ENTRE TIPO DE DOCUMENTO, TIPO DE AUTOR Y TIPO DE USUARIO. Como documentalistas y profesionales debemos tender a una difusión del contenido informativo, teniendo en cuenta la econóa detiempoy esfuezo para e usuario lo cual exige una sección previa de las existencias documentales atendiendo a criterios en los que primen los conocimientos aportados por los documentos y sus posibilidades de desarrollo. Respecto a la información científica, debemos proporcionar una información que impacte, que suscite en el investigador un tipo de efecto capaz de generar conocimiento; y ello es directamente proporcional a la proximidad entre el tipo de documento y el tipo de usuario.

Nos interesa no sólo la relación del usuario con el documento primario, sino también la del usuario con el documento secundario, que ha sido elaborado por el documentalista tratando de prever los distintos tipos de perfiles. Estos son factores que han de considerarse a la hora del diseño, construcción y evaluación de los sistemas de representación y organización de la información documental, ya que 
el éxito de una correcta recuperación de la información dependerá de la calidad de la organización.

\section{CONCLUSIÓN}

Esta exposición, como suele decirse, "apenas roza la supeficiedd tema." Con ella, sólo hemos pretendido - con mayor o menor acierto- llamar la atención sobre lanaturalezateéricadelosprddemasimplicadbsy sobre el estatuto de éstas dentro de un marco teórico integrador para el estudio del usuario de información.

Nuestro investigación supone, en todo caso, una limitada intervención afavor de una terna sistemática de usuarioque habrá de situarse en una encrucijada de diversas perspectivas. Dicha teoría presupone una teoría de la cognición social y una teoría de los contextos sociales implicados en la adquisición, reconocimiento, representación y uso de la información.

Si una perspetivateéricaes, sobre todo, un sistemavirtual depreguntas, en este artículo hemos hecho efectivas algunas interrogantes sobre el usuario. Nuevas preguntas nos darán nuevas respuestas.

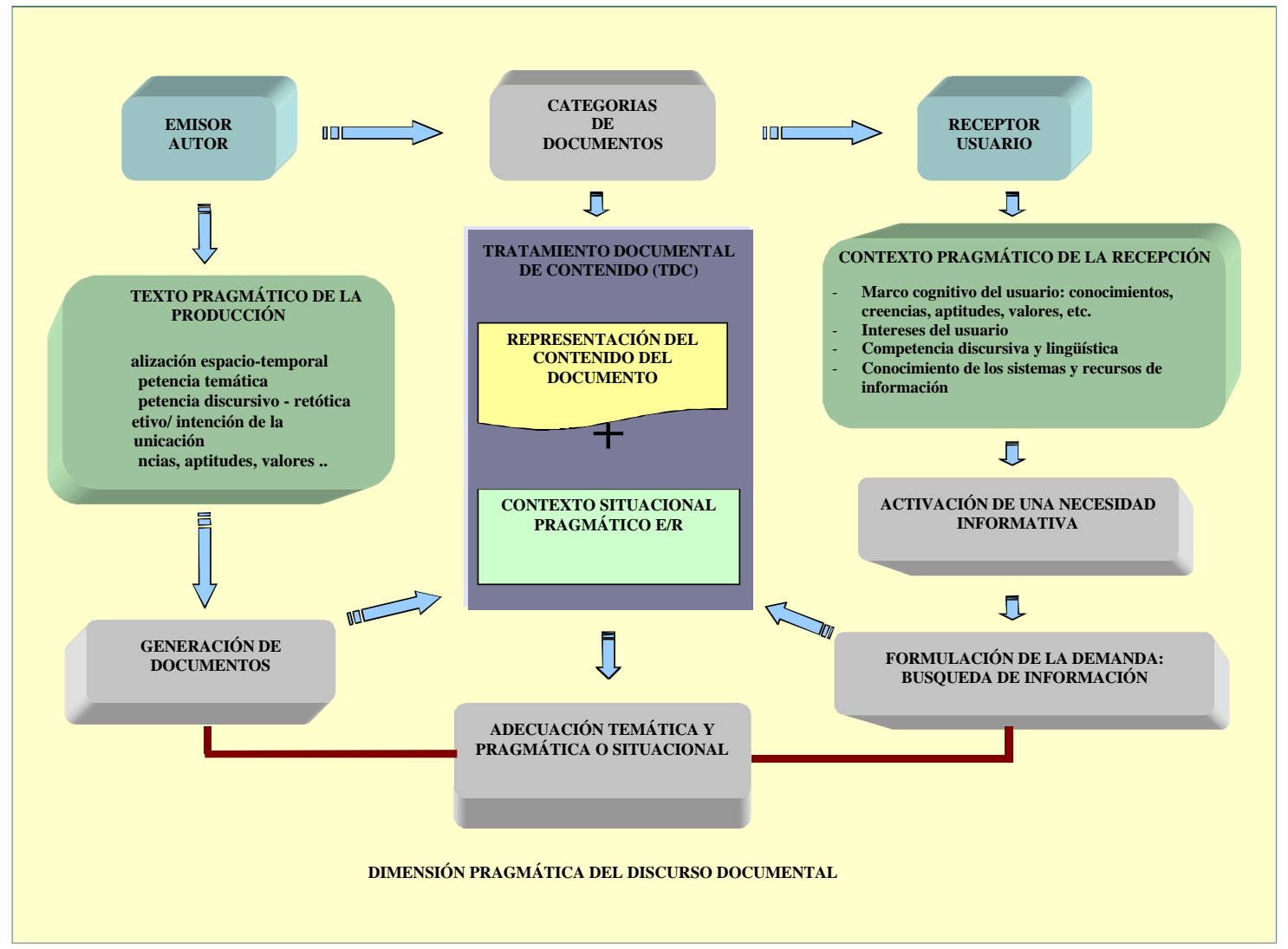

